\title{
Distracted driving prevention: an analysis of recent UK campaigns
}

\author{
Svenja Diegelmann, Katharina Ninaus and Ralf Terlutter \\ Department of Marketing and International Management, \\ Alpen-Adria-Universitaet Klagenfurt, Klagenfurt, Austria
}

\begin{abstract}
Purpose - The purpose of this paper is to analyze message features of fear appeals in current British road safety campaigns directed against mobile phone use while driving and to discuss barriers to explicit theory use in campaign message design.

Design/methodology/approach - This message-centred research takes a qualitative content analytical approach to analyze nine British web-based road safety campaigns directed against mobile phone use while driving based on the extended parallel process model. Message content and message structure are analyzed.

Findings - There still exists a gap between theory and road safety campaign practice. The study reveals that campaigns with fear appeals primarily use threatening messages but neglect efficacy-based contents. Severity messages emerge as the dominant content type while self-efficacy and response efficacy are hardly represented. Fear appeal content in the threat component was mainly communicated through the mention of legal, financial and physical harm, whereas efficacy messages communicated success stories and encouragement. As regards message structure, the threat component always preceded the efficacy component. Within each component, different patterns emerged.

Practical implications - To enhance efficacy in campaigns directed against distracted driving and to reduce the gap between theory and practice, social marketers should include messages that empower recipients to abstain from mobile phone use while driving. Campaigns should show recommended behaviours and highlight their usefulness and effectiveness.

Originality/value - This paper adds to limited research conducted on effect-independent message properties of fear appeals. It enhances understanding of fear appeal message features across the structure and content dimension. By discussing barriers to explicit theory use in social marketing practice and offering practical implications for social marketers, it contributes towards reducing the barriers to explicit theory use in campaign message design.
\end{abstract}

Keywords Social marketing, Road safety, Distracted driving, Fear appeals,

Extended parallel process model, United Kingdom, Accident prevention/road safety

Paper type Research paper

\section{Introduction}

Aimed at voluntary behaviour change of individuals, downstream social marketing campaigns play a vital role in addressing and reducing public health issues. They are widely used in the road safety context and are an effective measure to change different types

(C) Svenja Diegelmann, Katharina Ninaus and Ralf Terlutter. Published by Emerald Publishing Limited. This article is published under the Creative Commons Attribution (CC BY 4.0) licence. Anyone may reproduce, distribute, translate and create derivative works of this article (for both commercial \& non-commercial purposes), subject to full attribution to the original publication and authors. The full terms of this licence may be seen at http://creativecommons.org/licences/by/4.0/ legalcode

The authors gratefully acknowledge the reviewers and the editor for their valuable feedback and for sharing their expertise and ideas throughout the review process.

Received 13 July 2019 Revised 29 November 2019 16 January 2020 Accepted 16 January 2020 
JSOCM

10,2 of road user behaviours (Elder et al., 2004; Phillips et al., 2011; Tay, 2005). A prevalent and serious phenomenon resulting in impaired driving behaviour and increased crash risk is distracted driving due to mobile phone use (Strayer and Johnston, 2001; Strayer and Drew, 2004; Lipovac et al., 2017)[1]. In the UK, mobile phone use by drivers caused 423 road traffic collisions in 2018, resulting in 26 deaths, 95 seriously injured and 539 slightly injured road users (Department for Transport, 2019a, 2019b). The dark figure of mobile phone-related road traffic collisions is expected to be significantly higher than the official figures state (Department for Transport, 2015; Ige et al., 2016). To change road user behaviour, negative emotional appeals including fear appeals have been commonly used as a message design technique in road safety campaigns (Guttman, 2014; Tay and Watson, 2002). Existing theories such as the extended parallel process model (EPPM) (Witte, 1992) exist that can guide message design of fear appeals. Other models that share many similarities with the EPPM would be e.g. the health belief model (Rosenstock, 1966) or the protection motivation theory (Rogers, 1975). In their essence, these theories suggest that threatening communications should use threat-based and efficacy-based messages to achieve the largest effect (Kok et al., 2018). Several meta-analyses support this perspective (Peters et al., 2013; Tannenbaum et al., 2015; Witte and Allen, 2000). Nevertheless, there are indicators that realworld campaigns often do not comply with theory (Wundersitz et al., 2010; Wundersitz and Hutchinson, 2011; Algie, 2011), as they frequently include threat-based content while neglecting efficacy messages (Guttman, 2014).

Previous research in the field of real-world campaign analysis and fear appeals has mainly focussed on identifying theory-based message components in existing campaigns (Ngondo and Klyueva, 2019; Cismaru, 2014; Cismaru and Nimegeers, 2016). In those studies, messages were classified according to theoretical variables, however, neither further data analysis and explorations were reported, nor possible reasons for poor theory use discussed. Consequently, the insights remain limited. The aims of the present paper are twofold:

(1) to investigate how the message components of the EPPM are reflected in website texts and online videos of current road safety campaigns directed against mobile phone use in the UK; and

(2) to discuss possible reasons why practitioners apply fear appeals with a high focus on threat-based content in road safety while neglecting efficacy content.

Understanding how and why practitioners apply fear appeals in road safety is important for several reasons. First, theory-based insights into how existing fear appeals are designed contribute to a better understanding of message design in current campaign practice. Message design research has received relatively little attention in the scientific literature and there is a need to enhance the scientific understanding of applied emotional appeals and their message features, i.e. the effect-independent characteristics, the inherent message properties, of fear appeal messages (Cappella, 2006; O'Keefe, 2006; Slater et al., 2015). Second, a better understanding of the barriers to theory-based fear appeal application can be informative for future campaign evaluations. Third, by combining campaign analysis with barrier identification, more definitive facilitating strategies for better theory application, specifically for the inclusion of efficacy messages, can be developed. Traditionally, road safety campaigns used conventional media such as television, radio, print media and roadside signage to reach road users (Wilde, 1993). However, the delivery of digital content has become an increasingly important part of social marketing and road safety campaign practice (Faulks, 2011; Beall et al., 2012; Webb et al., 2010). The paper, therefore, focusses on digital campaign materials including websites and online videos. 


\section{Literature review}

\subsection{Fear appeals in social marketing}

To change harmful road user behaviours, fear appeals are commonly used in social marketing campaigns in the road safety context (Lewis et al., 2007; Tay, 2005). They are used in message design to achieve behaviour change through emotional engagement of the target audience. Fear appeals communicate the dangers of a behaviour and provide suggestions for how to change it (Witte, 1992). They are the source of emotional and cognitive processes that may result in persuasion and behaviour change (De Pelsmacker et al., 2011; Awagu and Basil, 2016).

The EPPM is a message design theory for fear appeals. In terms of message content, it posits that fear appeals have two main components, namely, the threat component and the efficacy component. The threat component consists of severity and susceptibility. Severity in a fear appeal is expressed by content communicating the dangers and negative consequences of a risky behaviour (LaVoie and Quick, 2013; Lapinski, 2006; Witte, 1992). Susceptibility is conveyed through messages that communicate the likelihood of experiencing the negative consequences resulting from a dangerous behaviour (Lapinski, 2006; Witte, 1992). To initiate behaviour change, the recipients need to perceive the dangers originating from the behaviour as voluntarily entered into, severe, and they need to perceive high efficacy (Donovan and Henley, 1997; Lewis et al., 2013). The efficacy component in a fear appeal can include recommended responses, response efficacy and self-efficacy messages. Recommended responses are concrete tips describing how to change the dangerous behaviour (Cismaru, 2014; Witte, 1992; Lapinski, 2006). Response efficacy messages highlight the usefulness and effectiveness of the recommendations and self-efficacy messages aim to enhance the recipients' ability to perform the proposed alternative behaviour (Witte et al., 1996).

A meta-analysis of experimental fear appeal studies conducted by Tannenbaum et al. (2015) concluded that fear appeals were generally effective in changing attitudes, intentions and behaviours; but the largest effects were achieved when efficacy components were included. This meta-analysis did not find negative effects in cases where fear appeals lacked efficacy components. However, the results of other empirical studies and meta-analyses demonstrate that the neglect of self- and response efficacy messages has negative consequences. The meta-analysis of experimental fear appeal studies conducted by Peters et al. (2013) showed an interaction effect for threat and efficacy; threat-based messages were only effective if efficacy was high and efficacy only had an effect if perceived threat was high. Under low efficacy, threat had negative effects on behaviour (Peters et al., 2013). Similarly, in quasi-experimental and experimental research, Shen (2011), Shen (2015) and Shen and Coles (2015) showed that fear appeals and loss-framed messages activate psychological reactance. People are overwhelmed by their emotions and do not consider behaviour change. The meta-analysis by Witte and Allen (2000) also concluded that high threat combined with low efficacy resulted in people responding defensively.

Apart from the importance of including threat and efficacy messages in fear appeals, the sequence and order of presenting the content is crucial, i.e. the message structure also plays an important role (Dillard and Shen, 2018). To influence behaviour change, the threat component should be communicated first, followed by the efficacy information (Dillard and Shen, 2018; Mongeau, 2012). On the micro stage of the threat component, susceptibility content should precede severity content and on the micro level of the efficacy component, response efficacy should come before self-efficacy messages (Dillard and Shen, 2018). For fear appeals to be effective, both message content and structure are important (Dillard and Shen, 2018; Dillard et al., 2016; Witte, 1994). 
JSOCM

10,2

2.2 Theory use in social marketing practice

Applying theory in behaviour change interventions, programs and campaigns is a key social marketing principle (Almestahiri et al, 2017; International Social Marketing Association, European Social Marketing Association and Australian Association of Social Marketing, 2013). It implies explicit theory use in the development and evaluation phase of social marketing activities. There is broad agreement in the literature on the relevance and usefulness of integrating explicit theories into campaign practice (Storey et al., 2015; Noar, 2006; Cappella, 2006; Peters et al., 2018; Lapinski and Witte, 1998). The benefits of applying suitable theory in downstream social marketing are manifold, including:

- a better understanding of the target behaviour and its determinants (Peters et al., 2018; Conner and Norman, 2015; Anderson, 2011);

- guidance for identifying, selecting and measuring variables of behaviour change (Valente, 2002; Fishbein and Cappella, 2006; Glasgow and Linnan, 2008);

- guidance for campaign goal and objective setting (Valente, 2002);

- a meaningful basis for segmenting target audiences (Storey et al., 2015; Noar, 2006; Delhomme et al., 2009); and

- guidance for message design (Cappella, 2006; Fishbein and Cappella, 2006).

Systematic reviews and meta-analyses of behaviour change interventions in various health contexts have shown that explicit theory use can enhance the effectiveness of interventions (Peters et al., 2009; Webb et al., 2010; Steinmetz et al., 2016; Taylor et al., 2012). In the traffic safety context, similarly, the evidence suggests that the use of formalized theories has a positive effect on intervention effectiveness (Elliott, 1993; Stead et al., 2004; Glendon and Walker, 2013). Nevertheless, in practice, the extent and rigour of theory application varies greatly (Helmig and Thaler, 2010; Wundersitz et al., 2010; Wundersitz and Hutchinson, 2011). For example, in their review of road safety campaign evaluation studies, Wundersitz and Hutchinson (2011) found that only 1 of 14 traffic safety campaigns was based on explicit theory. However, the chasm between research and practice is critical as best outcomes in message creation and, ultimately, the reduction of public health issues, can only be achieved through an interplay of science and practice (Cappella, 2006; Rothman, 2004; Glanz et al., 2015).

\subsection{Barriers to theory use in social marketing practice}

When reviewing and analyzing the literature, the key barriers to the use of theory in social marketing practice can be explained as follows: lack of knowledge, time constraints, perception of difficult applicability and excess of choice. First, limited knowledge appears to be a crucial barrier to theory use in campaign practice. This includes practitioners' limited knowledge of the variety of available theories, limited knowledge about the high potential of theory use in campaigns, limited knowledge about different behaviour change techniques and limited knowledge about cause-effect relationships that underlie threat messages (Peters et al., 2014; Davis et al., 2015; Davidoff et al., 2015). Second, the literature shows that time constraints in campaign development impede rigorous theory application. Campaigns are often driven by developers or stakeholders to achieve remarkable campaign effects within short periods of time (Watson et al., 2019; Peters et al., 2014; Glanz et al., 2015; Job, 1988). Campaigns, therefore, often opt for threatening messages, convinced that this will help them to attain their goals (Peters et al., 2014). Third, the application of theories in practice has been perceived as complicated and inhibiting by professionals when developing interventions or campaigns (O'Cathain et al., 2019; Davidoff et al., 2015; Aldoory et al., 2018; 
Dejong and Atkin, 1995; Rothman, 2004). Fourth, excess of choice refers to the variety of theories available, which, in practice, can result in decisional conflicts for practitioners (Damschroder, 2019; Michie et al., 2005; Noar, 2004). Apart from the four main barriers to theory use, an additional barrier related to the use of fear appeal theory in particular can be identified: false target audience assumptions. False target audience assumptions drive practitioners to use threat-based message design while neglecting efficacy messages (Hastings and MacFadyen, 2002; Peters et al., 2014; ten Hoor et al., 2012). Two phenomena are identifiable in this respect: First, there seems to be a prevalent belief that threatening messages are favoured by recipients (Hastings and MacFadyen, 2002). Second, practitioners often overestimate recipients' self-efficacy levels (ten Hoor et al., 2012; Peters et al., 2014), and therefore, rely on threat-based messages instead of also including efficacy components in their communications.

Bringing these barriers together, the paper aims to review and understand the link between theory and practice in message design of current British road safety campaigns directed against mobile phone use.

\section{Methods}

\subsection{Search strategy}

Following the data collection method of Cismaru (2014) and Nelson et al. (2011), a Google search was conducted to find publicly available materials of British road safety campaigns directed against mobile phone use on the internet. The key words used were "mobile phones" and "road safety" to identify nationwide campaigns. To discover local campaigns, the key words "road safety" and "mobile phones" were supplemented with every county and city in the UK. This was carried out systematically, as two alphabetically ordered lists of cities and counties were used to ensure that every city and county was covered in the key word search (Great Britain Economic and Trade Digest, 2017a; Great Britain Economic and Trade Digest, 2017b). In total, 66 cities and 70 counties were included. As the meta-analysis by Phillips et al. (2011) showed that many regional road safety campaigns exist, a mixture of national and local campaigns seemed most appropriate to capture the full spectrum of campaigns. In every search, the first five pages of search results were screened for relevant content. The first five pages were selected due to the decreasing relevance of the results from the sixth search results page onwards. The procedure of focussing on the first five pages of search results has previously been applied in other empirical studies (Tang and Ng, 2006; Singh et al., 2013; Harris et al., 2018; Nissan et al., 2018). Data collection was conducted over three separate eight-day periods in 2017.

The criteria for inclusion of a campaign were the following:

- The campaign has a campaign website and at least one campaign online video embedded in the website.

- The campaign website was released between the years 2014 and 2017.

- The campaign was run by an authority, institution, organization or business in the UK.

- In case the same originator released multiple campaigns directed against mobile phone use while driving throughout the data collection period, all campaigns were included. The communication campaign definition by Rogers and Storey (1987) was used as a theoretical underpinning for the inclusion criterion.

- The website texts and the online videos contained some degree of threat, which was apparent after the first screening. Websites and online videos, which use other appeals, such as humour, were excluded. 
JSOCM 10,2
Similar to de Hoog et al. (2007), a campaign was considered to apply fear appeals when it contained messages about the negative consequences of the target behaviour. More precisely, a campaign was included if messages about the dangers, negative consequences or seriousness of mobile phone use while driving were identifiable (Lapinski, 2006; LaVoie and Quick, 2013; Witte, 1992). There was no evidence that campaigns purposefully used fear appeal theories as theoretical underpinning. In the search process, nine campaigns with nine websites and 12 online videos were identified.

Post-test: To validate whether the sample of campaigns contained threatening communication, a post-test was conducted. The participants were 115 students (male 68 per cent, female 32 per cent; aged 19 to 42 years, $M=24.31$ ) enrolled at a European university. In total, 6 of the 12 online videos were randomly selected and served as stimuli. One video after the other was shown to the participants. After each video, participants completed a questionnaire:

- to characterize the content of the videos; and

- to report their emotional reactions to the videos.

First, participants assessed the extent to which the videos convey the dangers, negative consequences or seriousness of mobile phone use while driving on three seven-point semantic differential scales. The statements include "mobile phone use while driving is (safe/dangerous)", "mobile phone use while driving has (positive consequences/negative consequences)" and "mobile phone use is (problematic/not problematic)". The results validated the authors' classification of campaigns as containing threat-based messages $(\mathrm{M}=$ $6.50, \mathrm{SD}=0.92),(\mathrm{M}=6.54, \mathrm{SD}=0.93),(\mathrm{M}=6.48, \mathrm{SD}=0.92)$. In addition, the modified differential affect scale (Renaud and Unz, 2006) was used to assess the emotional reactions of the participants to the threat-based videos. Negative emotions (fear and sadness) and positive emotions (joy and amusement) were assessed based on a five-point Likert scale ("not at all" - "very much"). The one-sample $t$-test showed significantly higher negative emotions than positive emotions ( $p \leq 0.01$; negative emotions $\mathrm{M}=2.58, \mathrm{SD}=1.16$; positive emotions $\mathrm{M}=1.39, \mathrm{SD}=0.68$ ) in the participants. Similar to the first part of the post-test, these results validate the threat-based nature of the campaigns.

\subsection{Coding}

3.2.1 Segmentation. In preparation for coding, the websites and videos were saved locally and organized in folders marked with the retrieval date of the data. With regard to the website analysis, following the procedure by Lapinski (2006), the written content of the websites, mainly on the home pages, was considered for analysis. This seemed reasonable, as most of the websites only consisted of a home page and were largely text-based. The formal criteria of segmentation chosen for the websites were phrases or sentences (Schreier, 2012). In the segmentation process, the website texts were split into phrases, e.g. "and a fine of $£ 100$ " (C1, Table 1 for campaign indices) or sentences, e.g. "studies show that drivers using a hands-free or handheld mobile phone are slower at recognizing and reacting to hazards" (C3) based on content meaningfulness. The coding units were listed and numbered consecutively in a Word document file.

The overarching segmentation criteria for the online videos was written text, voice-over, oral communication of protagonists, audio sounds and visual images (Casais and Proença, 2015). The written text in the videos included all written communication visible in the videos, i.e. displayed text. The voice-over referred to the oral communication of an unseen narrator. In contrast, the third dimension, oral communication of protagonists represented the verbal communication uttered by people visible in the video. Audio sounds were noises and music in the video. The 


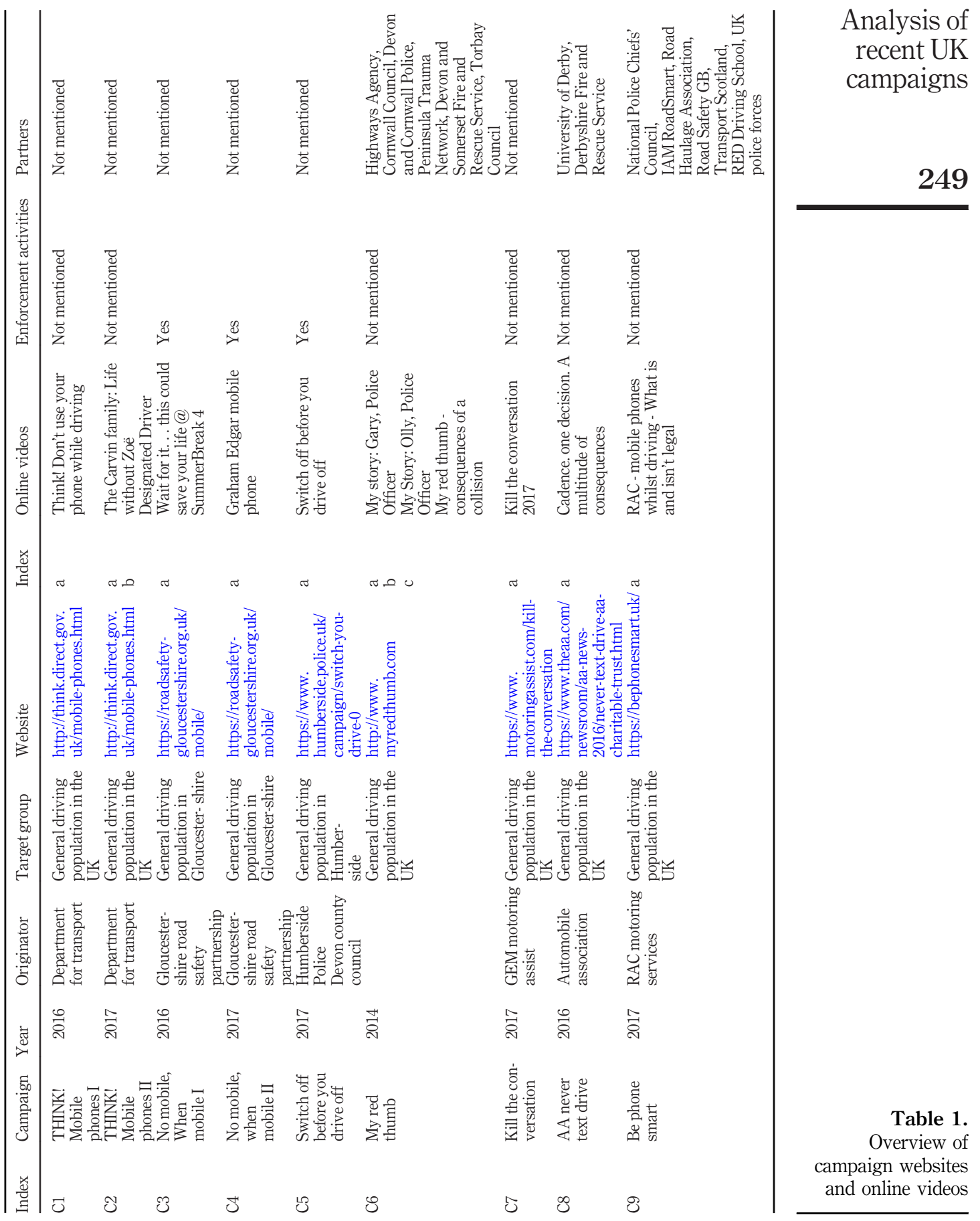


JSOCM 10,2

visual images included visual representations of objects, people, places or situations. For all videos, the written text, voice-over and oral communication of protagonists was manually transcribed by the author and saved in a Word document file. The audio sounds were also transcribed and included in the document. More precisely, brief descriptions were provided for every discernible sound, e.g. "ambulance siren" or "crash sound". The formal criteria of segmentation applied to the transcript, consisting of written text, voice-over, oral communication of protagonists and audio sounds were phrases or sentences (Schreier, 2012). Similar to the procedure for the website texts, the transcript was split into phrases or sentences considering content meaningfulness and every unit of coding was numbered consecutively. As a formal criterion of segmentation for the visual images, a fixed time interval of $2 \mathrm{~s}$ was applied. Every two-second time interval received a number. Consequently, all visual units of coding were numbered consecutively in a list to identify the coding units.

3.2.2 Coding frame development. Two coding frames with categories, sub-categories, definitions and examples were developed to ensure comparability within the website texts and online videos. The categories for both coding frames were developed deductively and inductively. Given that the central theoretical underpinning of the research was the EPPM, the message component variables of the EPPM, severity, susceptibility, recommended responses, self-efficacy and response efficacy were used as broad, deductive categories. This procedure was in accordance with Lapinski (2006), who also considered five theoretical variables of the EPPM in the analysis. The category definitions were adapted from the literature including Witte et al. (1996), Lapinski (2006), LaVoie and Quick (2013) and Cismaru (2014). The definition of severity and susceptibility were adapted from Witte et al. (1996), Lapinski (2006) and LaVoie and Quick (2013). Self-efficacy and response efficacy definitions were adapted from Witte et al. (1996) and Lapinski (2006). The definition of recommended responses was adapted from Cismaru (2014) and Lapinski (2006). To determine the sub-categories of the EPPM categories and other main categories, a combined deductive-inductive approach to category development was applied. Essentially, all data were screened in an iterative, data-driven process (Schreier, 2012) until exhaustion of categories was achieved. The inductively built categories and sub-categories were crosschecked with the literature and some were renamed and refined based on categories put forward by Donovan and Henley (1997), Atkin and Rice (2012), Guttman (2014), Guttman (2015) and Nelson et al. (2011). In a pilot phase, both coding frames were tested with half of the websites and half of the videos of the original data set. This involved assigning a code to every unit of coding and recording it in an Excel coding sheet. After the trial coding, adjustments to categories and definitions were made to enhance exhaustiveness, saturation and mutual exclusiveness of categories (Schreier, 2012).

\subsection{Data analysis}

Qualitative content analysis by Schreier (2012) was used for data analysis. The main coding phase was split into two stages. The full data set was first coded by one researcher and subsequently recoded independently by another researcher to check for inter-coder reliability. The percentage of agreement for the websites was 89.58 per cent and 95.67 per cent for the videos, which indicates high consistency and high inter-coder reliability (Miles and Huberman, 1994). After the independent coding processes, the researchers compared the codes and highlighted any differences. During a follow-up discussion, both coders agreed on a final code for every unit of coding (Schreier, 2012). Based on the results of the coding, further data explorations for patterns and relationships of the categories (Schreier, 2012) were conducted. 


\section{Findings}

The sample consisted of nine web-based road safety campaigns. The majority were nationwide campaigns $(n=6)$. Three were local campaigns. All campaigns targeted general driving populations in the UK, either nationwide or in regional areas. The nine campaigns consisted of websites $(n=9)$ and online videos $(n=12)$. Table 1 presents campaign details.

\subsection{Frequency of threat and efficacy messages}

Across all websites and videos analyzed, a total of 794 references to EPPM categories were found. In total, threat-based content occurs 693 (of 794, i.e. 87.3 per cent) times across websites and videos in contrast to efficacy-based content, which appears only 101 (of 794, i.e. 12.7 per cent) times, demonstrating a clearly imbalanced allocation of the content among the different EPPM categories. Sub-divided into the different message component variables, the uneven distribution becomes even more pronounced. Severity is the threat category used most intensively. All websites and videos contain severity content. Both on the websites and in the videos, more than half of the content related to the EPPM belongs to this category, signifying the pervasiveness of this theme. The threat component susceptibility, in comparison, plays a minor role on websites and in the videos. While all websites contain susceptibility messages, only 50 per cent of the videos include them. According to the EPPM, the efficacy elements of fear appeals are of equal importance, though underused in the analyzed campaigns. The most prevalent of the three efficacy sub-categories is recommended responses. Eight websites and nine videos contain recommended responses. Considering the two remaining message component variables, self-efficacy and response efficacy, together they comprise the other half of the efficacy-based messages. For each EPPM message component variable, the absolute frequencies of EPPM messages and the percentage of messages are displayed in Table 2.

\subsection{Fear appeals in website texts}

4.2.1 Message structure. Across all website texts that included both threat and efficacy messages $(n=7)$, the threat component preceded the efficacy component. More precisely, there was no website text that introduced efficacy messages before having communicated a threatening message on the site. Narrowed down to the level of the different EPPM categories, four structures were identified. The three most common structures were:

- introduction of susceptibility messages followed by severity messages ( $n=2 / 7)$;

- introduction of severity messages followed by susceptibility messages $(n=2 / 7)$; and

- introduction of susceptibility messages followed by recommended responses $(n=2 / 7)$.

\begin{tabular}{lcccrrr}
\hline & \multicolumn{3}{c}{ Absolute frequency of EPPM messages } & \multicolumn{2}{c}{$\%$ of EPPM messages } & \\
Variable & Websites & Videos & Total & Websites (\%) & Videos (\%) & \\
\cline { 1 - 2 } Severity & 94 & 532 & 626 & 50.81 & 87.35 & \\
Susceptibility & 48 & 19 & 67 & 25.96 & 3.12 & Table 2. \\
Recommended responses & 28 & 21 & 49 & 15.13 & 3.45 & Numerical website \\
Self-efficacy & 11 & 24 & 35 & 5.94 & 3.95 & and video analysis \\
Response efficacy & 4 & 13 & 17 & 2.16 & 2.13 & results \\
Total & 185 & 609 & 794 & 100 & & \\
\hline
\end{tabular}

$+2$ 
JSOCM

10,2

For example, for structure (b): From 1 March, the penalties for holding and using your phone while driving have increased. [Code: Severity] It’s now six points [Code: Severity] and $£ 200$ [Code: Severity]. The facts: Drivers using a hands-free or handheld mobile phone are slower at recognizing and reacting to hazards. [Code: Susceptibility] Research shows: You are four times more likely to be in a crash if you use your phone. [Code: Susceptibility] (C2). Besides, another pattern occurred, namely, (d) introduction of severity messages followed by recommended responses $(n=1 / 7)$.

As regards arrangement of the messages in the further body of the texts, two patterns were identified. On most sites that included both threat and efficacy messages, the efficacy messages were sprinkled throughout the text $(n=4 / 7)$, which meant a mixture of threat and efficacy messages in terms of arrangement. In contrast, three websites bundled the efficacy messages close to the end of the text after all threat message had been communicated $(n=3 / 7)$.

Within the threat components of websites that contained both severity and susceptibility messages $(n=8)$, three sequence structures were visible:

- susceptibility messages communicated in a block prior to the severity messages $(n=3 / 8)$

- a block of severity messages communicated first, followed by susceptibility messages and again by severity messages $(n=3 / 8)$; and

- a block of susceptibility messages first, followed by severity messages and again by susceptibility messages $(n=2 / 8)$.

Concerning the efficacy component, only two website texts use both response efficacy and self-efficacy messages $(n=2)$. In these two texts, self-efficacy occurs before the first response efficacy message is communicated. One website ends with a self-efficacy message, whereas the other ends with a response efficacy message.

4.2.2 Message content. Figure 1 presents a graphic illustration of the EPPM categories with selected, inductively derived sub-categories, examples and interrelationships for the website content.

On all websites $(n=9)$, messages are included that highlight the negative consequences of mobile phone use while driving. Two prominent severity themes that emerge are legal and financial harm. For example, "if you are caught using a handheld phone while driving, you'll get six penalty points on your license" (C2), "you will lose your license" (C1) or "if you are caught its a $£ 200$ fine" (C6). The themes legal and financial harm co-occur on most of the websites $(n=7)$. Legal harm is communicated on all sites, but instead of financial harm, additional themes including physical or moral harm are addressed on the two remaining sites.

On eight websites, the EPPM category of susceptibility is communicated through messages showing recipients the high probability of experiencing the harmful consequences when using a mobile device while driving. Personal relevance of the threat-based messages is, thus, established, for example, "even careful drivers can be distracted by a call or textand a split-second lapse in concentration could result in a crash" (C1). Besides, it is communicated that distracted driving has become an omnipresent phenomenon on today's roads, for example, "it is a behaviour seen too frequently on our roads" (C3).

Recommended responses for drivers and for people outside the car were communicated on the websites. Table 3 shows the action types with examples from the data. In terms of response efficacy content, messages were present on the sites that demonstrated to the recipients what following the recommended behaviour meant for them and/or for others 


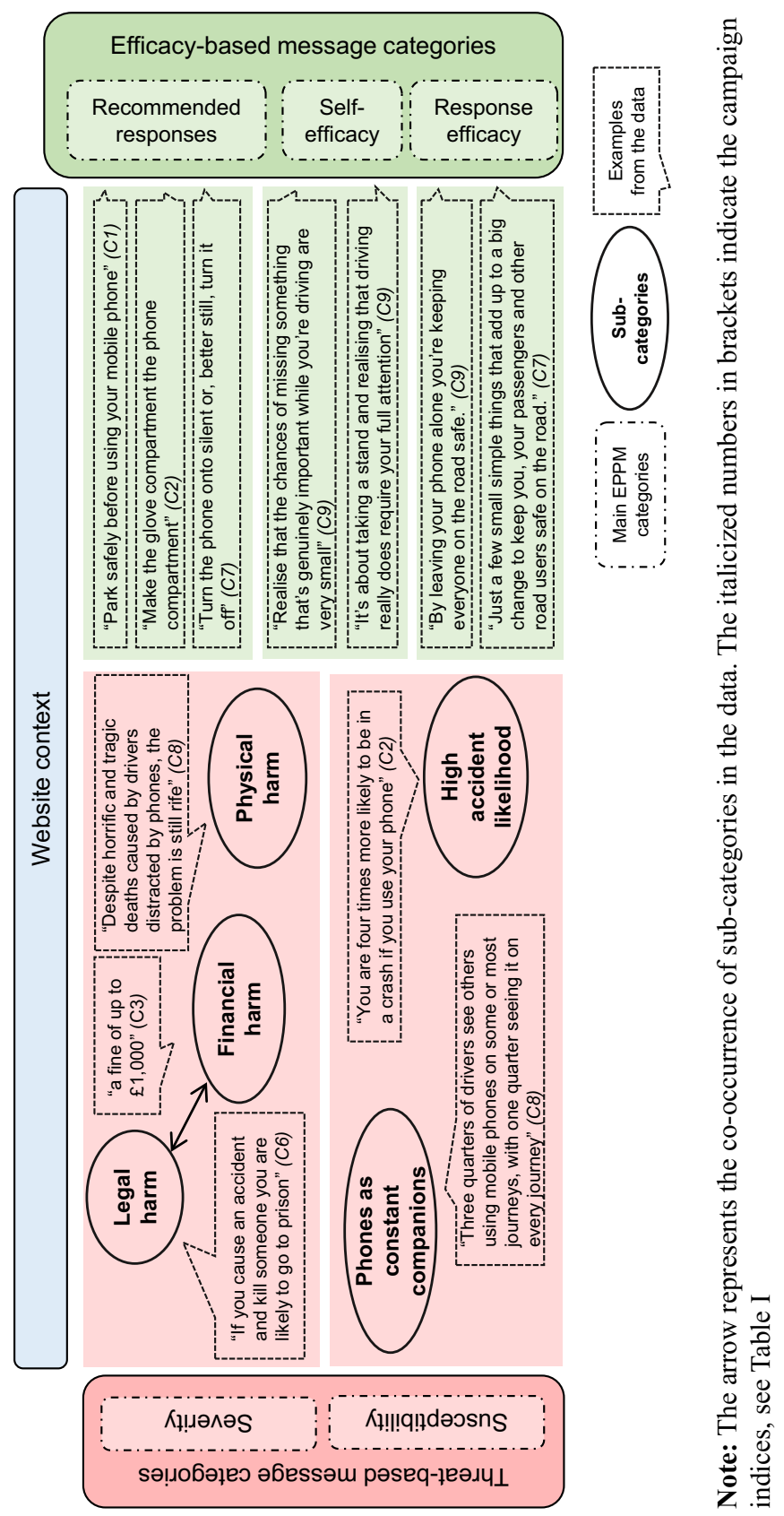

Analysis of recent UK campaigns

253

Figure 1. EPPM categories (Witte, 1992) with inductively developed sub-categories, examples and interrelationships 
JSOCM

10,2

\section{4}

(Figure 1 for examples). The self-efficacy messages aimed at encouraging the recipients in their ability to pursue the recommended behaviour, for example, "so get into the habit now of leaving the phone alone" (C4).

\subsection{Fear appeals in online videos}

4.3.1 Message structure. Similar to the campaign websites, all videos that communicated threat and efficacy messages $(n=10)$ presented threat-based content prior to efficacy information. Efficacy messages mostly appeared towards the end of the videos through oral communication of the protagonists or written text. Concerning the different EPPM components and all video dimensions, severity content was exclusively presented first in all videos.

The efficacy component subsequent to the severity content took several forms. The two most common patterns were an efficacy component consisting of recommended responses and response efficacy content $(n=3 / 10)$ or recommended responses only $(n=3 / 10)$. In two videos, the efficacy component consisted of recommendations and self-efficacy messages $(n=2 / 10)$. The full range of efficacy messages was only exploited in two videos $(n=2 / 10)$. Interestingly, those videos also included susceptibility messages, which were present in only four other campaign videos.

4.3.2 Message content. Figure 2 presents a graphic illustration of the EPPM categories with selected, inductively developed sub-categories, examples and interrelationships for the online video content.

All videos $(n=12)$ contained severity content. Severity was expressed through all five video dimensions, namely, written text, voice-over, oral communication of protagonists, audio sounds and visual images. In the dimensions written text, voice-over and oral

\footnotetext{
Recommended responses for drivers

Switching off "Switch off before you drive off" (C1)

"Riders switch off their phones before they turn the engine on" (C4)

"Your best bet is to turn it off" (C7)

Park before use "Park safely before using your mobile phone" (C1)

"Find a safe place to stop first" (C4)

"Our advice - wait until you're parked safely!" (C7)

Place out of reach "Put your phone away before driving so you won't be tempted to use it" (C2)

"Make the glove compartment the phone compartment" (C2)

"If you know or think, you're tempted to use a handheld phone at the wheel, put it away" (C9)

Use before drive "If you need to call someone or check an e-mail give yourself a couple of minutes to do that before you get in the car" (C7)

Pledge "Help make the roads safer for all of us - make a promise today to your friends and family to Be Phone Smart” (C9)

Recommended responses for people outside the car

Be considerate "Don't call other people when they're driving" (C2)

"If you call someone and they tell you they are driving, ask them to call you back when they have parked up safely" (C5)
}

Table 3.

Matrix with types of actions and examples from the websites 

JSOCM 10,2

communication of protagonists, the severity messages were similar to the messages on the websites. Nevertheless, one type of severity message exclusive to the videos was testimonials of police officers who deliver death messages to relatives, testimonials of bereaved people and testimonials of a car crash survivor. Their real-life stories about fatal crashes indicate tragedy and established a direct relationship between mobile phone use and the negative consequences. Figure 2 displays the sub-categories details of the crash, suffering of the relatives, physical harm and delivering the death message, which originated from testimonials in the videos.

A small number of audio sounds $(n=10)$ that express severity were used in a minority of videos $(n=4)$. The audio effects include collision sounds, alarms, emergency braking sounds, glass shattering or ambulance sirens.

In the video dimension visual images, severity was conveyed through different themes. First, as dramatized graphic portrayals (Guttman, 2015), themes such as victim in crashed car, dying victim in someone's arms or dead body occurred (Figure 2). In addition, related to testimonials, images of a real victim of a mobile phone-related road traffic collision were portrayed in one video (C3a). Besides, in two videos, symbols including a skull, explosion, loudly crying face emoji or cracked mobile phone screen clipart were used to communicate the danger and negative consequences of mobile phone use while driving (C5a, C7a). Finally, images of nonverbal communication that show emotional devastation or shock conveyed severity in the videos (C1a, C3a).

Susceptibility messages, coded in the video dimensions written text, voice-over and oral communication of protagonists of the videos, were similar to the messages in the website texts (Figures 1 and 2).

In congruence with the websites, the recommendations in the online videos focussed on drivers and people outside the vehicle. Nevertheless, a new group was addressed, namely passengers. For example, "and if you are in the passenger seat and somebody uses it, tell them to stop" (C6b). Concerning self-efficacy content, the most interesting sub-category that emerged was success stories (Nelson et al., 2011). It included statements of interviewees who described their behavioural intentions of abstaining from mobile phone use while driving, for example, "if I see it ringing or I get a text - in the future I'm just gonna lock it into the boot of the car where I cannot be distracted by it" (C7a) or "I'm not going to use my phone and drive and not gonna do it when I go to work tomorrow and the next day after that until you know it becomes a habit and it just does not happen at all”(C3a).

\section{Discussion}

The qualitative investigation of current web-based road safety campaigns directed against distracted driving based on the EPPM highlighted potentially important limitations in campaign message design. There are three central discussion points that arise from the analysis of current web-based road safety campaigns directed against distracted driving.

\subsection{Neglect of efficacy messages}

Our results illustrate that recent road safety campaigns with fear appeals continue to use threatening messages while neglecting efficacy components. The findings are further evidence of a gap that exists between theory and practice in road safety campaigns (Cismaru, 2014; Ngondo and Klyueva, 2019). In light of the EPPM and empirical literature, the reliance on threat-based content is critical, as this is likely to impair fear appeal effectiveness (Shen and Coles, 2015; Brennan and Binney, 2010; Quick et al., 2018; Hastings et al., 2004; Aldoory and Bonzo, 2005). Although there is agreement in the literature about the benefits that explicit theory use has for message design in campaign practice, our results 
illustrate that the barriers to theory application seem to be omnipresent in practice. The five barrier categories outlined in the literature review, lack of knowledge, time constraints, perception of difficult applicability, excess of choice and false target audience assumption are potential explanations for the neglect of efficacy components in the analyzed campaigns. Further research is needed to determine which barrier type has the greatest effect on campaign developers in the road safety context. Overall, the neglect of response and selfefficacy messages in the campaign sample indicates the need for facilitation strategies that specify how efficacy components can be integrated into road safety campaigns. Similarly, Kok et al. (2018) and Peters et al. (2014) call for clearer recommendations of how to increase self-efficacy in behaviour change interventions.

\subsection{Deficits in fear appeal structure}

In all website texts and videos that included both threat and efficacy messages, threat content was communicated prior to efficacy messages. This meta level sequence is in accordance with theoretical considerations in the literature (Dillard and Shen, 2018; Mongeau, 2012; Shen and Coles, 2015). However, on the micro stage, various patterns occurred in the campaigns, not all consistent with the recommended message sequence of susceptibility $\rightarrow$ severity $\rightarrow$ response efficacy $\rightarrow$ self-efficacy (Dillard and Shen, 2018). Obviously, there is a great variety of fear appeal structuring that is used in campaign practice and further research is needed to gain a better understanding of the effectiveness of the different structures.

\subsection{Content dynamics of fear appeals}

According to our findings, campaign websites and online videos directed against mobile phone use while driving use a variety of content themes to communicate threat and efficacy. For threatening communications, legal and financial consequences were highlighted on the websites. These co-occurring content themes are congruent with Guttman (2014), who identified loss of one's driving license as a theme in various road safety campaigns. Similarly, mruk Ltd (2004) showed that the threats of penalty points, loss of driving license and the threat of having to pay a fine were the most influential threats in a Scottish anti-drink driving campaign. In line with previous research (Guttman, 2014; Cismaru, 2014), testimonials were identified in campaigns. Our findings illustrate various interrelated severity themes within testimonials of people directly affected by mobile phone-related road traffic collisions. The themes emerged in language-based content and visual images.

Although low frequencies of efficacy messages occurred, our analysis of the message features showed various relevant and specific recommended responses for drivers and others. The tips for drivers are in line with previously identified suggestions (Cismaru, 2014). The success stories and encouraging messages represented self-efficacy enhancing content. According to Nelson et al. (2011) and Guttman (2014), success stories are highly appropriate for communicating efficacy in campaigns.

\subsection{Implications}

Our research contributes towards closing the gap between theory and practice through a theory-based analysis of real-world campaigns, the discussion of potential barriers to campaign message design, and the development of practical recommendations for future campaigns. The results showed a neglect of efficacy messages in the campaigns. To bridge the gap between theory and practice, facilitating strategies for enhancing self-efficacy and response efficacy in web-based road safety campaigns are proposed based on the analysis of the real-world campaign sample. In this vein, the call for clearer explanations on how to
Analysis of recent UK campaigns 
JSOCM

10,2

increase self-efficacy in behaviour change interventions will be addressed (Kok et al., 2018; Peters et al., 2014).

To enhance self-efficacy: Illustrate success stories of drivers who have found useful ways for themselves to change their behaviour from mobile phone use behind the wheel to undistracted driving in everyday life. It includes telling or visually showing precisely what strategies they use, e.g. lock phone away, airplane mode, use of apps to prevent distracted driving, that helped them change their behaviour. Personal stories from a variety of drivers should be included to target different age groups or types of drivers. By letting them tell their personal, positive experiences with changing behaviour, they will function as encouragement for campaign recipients.

To enhance response efficacy: The success stories need to highlight that the selected strategies of the drivers have been effective in avoiding negative consequences of mobile phone use while driving. These consequences can include a road traffic collision or legal or financial harm due to mobile phone use. If success stories verbally or visually demonstrate that recommended responses are highly useful in everyday life and lead to effective outcomes, recipients are more likely to adopt them.

Apart from the recommendations, we contribute to the scientific understanding of the message design of fear appeals. Much of previous research has focussed on message effect research and little is known about the science of fear appeal message design (Cappella, 2006; O'Keefe, 2006). Our results illustrate effect-independent message features of fear appeals that are used in current campaign practice. Through the lens of the EPPM, we contribute to theoretically-based insights into message properties and structures of fear appeals. We identify different patterns of ordering the threat and efficacy component. As patterns cooccurred across campaigns, they might be worth analyzing in future message effect research. The various content themes the analysis revealed contribute to the existing pool of themes that might be used for campaign message design and variations in practice. Additionally, they might be used for future message effect research to examine perceived and actual message effectiveness of certain message types and combinations.

Similar to previous studies, our research showed a gap between research and practice; more precisely, the use of threat-based message design while neglecting efficacy. By outlining precise practical recommendations for enhancing self-efficacy and response efficacy in road safety campaign practice based on previously identified barriers, we contribute towards closing the theory and application gap. Several authors (Cappella, 2006; Rothman, 2004; Glanz et al., 2015) have highlighted that to move the entire field forward, an interplay of theory and practice is needed to achieve best outcomes.

\subsection{Limitations and future research}

The study has certain limitations that indicate avenues for further research. Even though the qualitative analysis yields insightful results, the qualitative nature of the study limits the generalizability of the findings as well as the implications. Future studies might apply a quantitative approach to content analysis to investigate the relationships between different media forms, as for example, television and print media and each EPPM variable. Another limitation is that for the coding process, the online videos were fragmented into five video dimensions. This might bear issues, as the recipients' perceptions of a video might not be based on single video dimensions. In our study, we coded efficacy and susceptibility messages only in the language-based dimensions of the videos. In the future, attempts could be made to identify efficacy and susceptibility also in the non-language-based video parts. The findings of the present research demonstrate a variety of message structures that are used for fear appeals in real campaigns. Future research might examine and elaborate on the 
most effective structures of message components. Apart from fear appeals, other emotional appeal types such as humour appeals exist that might be worth investigating with regard to their prevalence and effectiveness in real-world campaigns. Besides, all analyzed campaigns were targeted at general driving populations in the UK. In future research, it might be interesting to examine campaigns that are adapted to specific target audiences. Moreover, as the campaign sample in the present study included national and regional campaigns, future research could examine the differences between national and regional campaigns in more detail. Furthermore, the geographic focus of the research was solely based on the UK. Instead of focussing on campaigns from one country, future studies could take a comparative approach and examine road safety campaigns directed against mobile phone use while driving as deployed in different countries. Concerning practitioners' barriers of theory use, future studies could apply expert interview or focus group methods to gain new and additional insights into barriers of message design and theory application in road safety. Finally, it would be interesting to conduct an analysis similar to this research on existing campaigns that have already been assessed for their effectiveness. Consequently, a comparison of both evaluations could bring new insights into the use and effectiveness of fear appeals.

\section{Note}

1. The word mobile phone refers to nomadic devices. These are "all portable electronic devices for information, entertainment or communication that can be used outside of the vehicle and inside the vehicle by the driver whilst driving" (Janitzek et al., 2010, p. 10).

\section{References}

Aldoory, L. and Bonzo, S. (2005), "Using communication theory in injury prevention campaigns", Injury Prevention, Vol. 11 No. 5, pp. 260-263.

Aldoory, L., Roberts, E.B., Bushar, J. and Assini-Meytin, L.C. (2018), "Exploring the use of theory in a national text message campaign: addressing problem recognition and constraint recognition for publics of pregnant women", Health Communication, Vol. 33 No. 1, pp. 41-48.

Algie, J. (2011), "The importance of fear reduction in fear-based road safety advertising appeals", Journal of the Australasian College of Road Safety, Vol. 22 No. 4, pp. 99-105.

Almestahiri, R., Rundle-Thiele, S., Parkinson, J. and Arli, D. (2017), "The use of the major components of social marketing:a systematic review of tobacco cessation programs", Social Marketing Quarterly, Vol. 23 No. 3, pp. 232-248.

Anderson, D.S. (2011), "Persuasion and motivational messaging", in Porter, B.E. (Ed.), Handbook of Traffic Psychology, Academic Press, San Diego, pp. 423-439.

Atkin, C.K. and Rice, R.E. (2012), "Theory and principles of public communication campaigns”, in Rice, R.E. and Atkin, C.K. (Eds), Public Communication Campaigns, 4th ed., Sage, Thousand Oaks, CA, pp. 3-19.

Awagu, C. and Basil, D.Z. (2016), "Fear appeals: the influence of threat orientations", Journal of Social Marketing, Vol. 6 No. 4, pp. 361-376.

Beall, T., Wayman, J., D’Agostino, H., Liang, A. and Perellis, C. (2012), "Social marketing at a critical turning point", Journal of Social Marketing, Vol. 2 No. 2, pp. 103-117.

Brennan, L. and Binney, W. (2010), "Fear, guilt, and shame appeals in social marketing", Journal of Business Research, Vol. 63 No. 2, pp. 140-146.

Cappella, J.N. (2006), "Integrating message effects and behavior change theories: Organizing comments and unanswered questions", Journal of Communication, Vol. 56 No. S1, pp. S265-S279.

\section{Analysis of recent UK campaigns}

$-2$


JSOCM 10,2

Casais, B. and Proença, J.F. (2015), "A model to classify television social advertisements according to the use of positive or negative appeals", in Banks, I.B., De Pelsmacker, P. and Okazaki, S. (Eds), Advances in Advertising Research (Vol. V): Extending the Boundaries of Advertising, Springer Gabler, Wiesbaden, pp. 15-27.

Cismaru, M. (2014), "Using the extended parallel process model to understand texting while driving and guide communication campaigns against it", Social Marketing Quarterly, Vol. 20 No. 1, pp. 66-82.

Cismaru, M. and Nimegeers, K. (2016), "Keep your eyes up, don't text and drive': a review of anti-texting while driving campaigns' recommendations", International Review on Public and Nonprofit Marketing, pp. 1-23.

Conner, M. and Norman, P. (2015), "Predicting and changing health behaviour: a social cognition approach", in Conner, M. and Norman, P. (Eds), Predicting and Changing Health Behaviour: Research and Practice with Social Cognition Models, 3rd ed., Open University Press, Maidenhead, pp. 1-29.

Damschroder, L.J. (2019), "Clarity out of chaos: Use of theory in implementation research", Psychiatry Research, available at: https://doi.org/10.1016/j.psychres.2019.06.036

Davidoff, F., Dixon-Woods, M., Leviton, L. and Michie, S. (2015), "Demystifying theory and its use in improvement”, BMJ Quality and Safety, Vol. 24 No. 3, pp. 228-238.

Davis, R., Campbell, R., Hildon, Z., Hobbs, L. and Michie, S. (2015), "Theories of behaviour and behaviour change across the social and behavioural sciences: a scoping review", Health Psychology Review, Vol. 9 No. 3, pp. 323-344.

de Hoog, N., Stroebe, W. and de Wit, J.B.F. (2007), "The impact of vulnerability to and severity of a health risk on processing and acceptance of fear-arousing communications: a meta-analysis", Review of General Psychology, Vol. 11 No. 3, pp. 258-285.

De Pelsmacker, P., Cauberghe, V. and Dens, N. (2011), "Fear appeal effectiveness for familiar and unfamiliar issues", Journal of Social Marketing, Vol. 1 No. 3, pp. 171-191.

Dejong, W. and Atkin, C.K. (1995), "A review of national television PSA campaigns for preventing alcohol-impaired driving, 1987-1992”, Journal of Public Health Policy:; Vol. 16 No. 1, available at: www.jstor.org/stable/3342977

Delhomme, P. de Dobbeleer, W. Forward, S. and Simões, A. (2009), "Manual for designing, implementing, and evaluating road safety communication campaigns: Prart I", available at: www.vias.be/storage/main/cast-manual-final.pdf (accessed 4 November 2019).

Department for Transport (2015), "Reported road casualties Great Britain: 2014 annual report", available at: www.gov.uk/government/uploads/system/uploads/attachment_data/file/467465/ rrcgb-2014.pdf (accessed 14 November 2018).

Department for Transport (2019a), "RAS50001 contributory factors in reported accidents by severity, Great Britain, 2018”, available at: https://assets.publishing.service.gov.uk/government/uploads/ system/uploads/attachment_data/file/833827/ras50001.ods

Department for Transport (2019b), "RAS50007 casualties in reported accidents by contributory factor and severity, Great Britain, 2018", available at: https://assets.publishing.service.gov.uk/ government/uploads/system/uploads/attachment_data/file/833833/ras50007.ods

Dillard, J.P., Li, R., Meczkowski, E., Yang, C. and Shen, L. (2016), "Fear responses to threat appeals: functional form, methodological considerations, and correspondence between static and dynamic data", Communication Research, Vol. 44 No. 7, pp. 997-1018.

Dillard, J.P. and Shen, L. (2018), "Threat appeals as multi-emotion messages: an argument structure model of fear and disgust", Human Communication Research, Vol. 44 No. 2, pp. 103-126.

Donovan, R.J. and Henley, N. (1997), "Negative outcomes, threats and threat appeals: Widening the conceptual framework for the study of fear and other emotions in social marketing communications", Social Marketing Quarterly, Vol. 4 No. 1, pp. 56-67.

Elder, R.W., Shults, R.A., Sleet, D.A., Nichols, J.L., Thompson, R.S. and Rajab, W. (2004), "Effectiveness of mass media campaigns for reducing drinking and driving and alcohol-involved crashes: a systematic review", American Journal of Preventive Medicine, Vol. 27 No. 1, pp. 57-65. 
Elliott, B. (1993), "Road safety mass media campaigns: a Meta analysis", available at: https:// infrastructure.gov.au/roads/safety/publications/1993/pdf/Edu_Media_1.pdf (accessed 29 October 2019).

Faulks, I. (2011), "Road safety advertising and social marketing", Journal of the Australasian College of Road Safety, Vol. 22 No. 4, pp. 34-40.

Fishbein, M. and Cappella, J.N. (2006), "The role of theory in developing effective health communications", Journal of Communication, Vol. 56 No. S1, pp. S1-S17.

Glanz, K., Rimer, B.K. and Viswanath, K. (2015), "Theory, research, and practice in health behavior", in Glanz, K., Rimer, B.K. and Viswanath, K. (Eds), Health Behavior: Theory, Research, and Practice, 5th ed., Jossey-Bass, San Fransisco, pp. 23-41.

Glasgow, R.E. and Linnan, L.A. (2008), "Evaluation of theory-based interventions", in Glanz, K., Rimer, B.K. and Viswanath, K. (Eds.) Health Behavior and Health Education: Theory, Research, and Practice, Jossey-Bass, San Fransisco, pp. 487-508.

Glendon, A.I. and Walker, B.L. (2013), "Can anti-speeding messages based on protection motivation theory influence reported speeding intentions?", Accident Analysis and Prevention, Vol. 57, pp. 67-79.

Great Britain Economic and Trade Digest (2017a), "List of UK cities", available at: www.gbet.com/ AtoZ_cities/ (accessed 14 November 2018).

Great Britain Economic and Trade Digest (2017b), "List of UK counties”, available at: www.gbet.com/ AtoZ_counties (accessed 14 November 2018).

Guttman, N. (2014), Communication, Public Discourse, and Road Safety Campaigns: Persuading People to Be Safer, Routledge, New York, NY.

Guttman, N. (2015), "Persuasive appeals in road safety communication campaigns: Theoretical frameworks and practical implications from the analysis of a decade of road safety campaign materials", Accident Analysis and Prevention, Vol. 84, pp. 153-164.

Harris, V.C., Links, A.R., Hong, P., Walsh, J., Schoo, D.P., Tunkel, D.E., Stewart, C.M. and Boss, E.F. (2018), "Consulting Dr. Google: quality of online resources about tympanostomy tube placement", The Laryngoscope, Vol. 128 No. 2, pp. 496-501.

Hastings, G. and MacFadyen, L. (2002), "The limitations of fear messages", Tobacco Control, Vol. 11 No. 1, pp. 73-75.

Hastings, G., Stead, M. and Webb, J. (2004), "Fear appeals in social marketing: Strategic and ethical reasons for concern", Psychology and Marketing, Vol. 21 No. 11, pp. 961-986.

Helmig, B. and Thaler, J. (2010), "On the effectiveness of social marketing — what do We really know?", Journal of Nonprofit and Public Sector Marketing, Vol. 22 No. 4, pp. 264-287.

Ige, J., Banstola, A. and Pilkington, P. (2016), "Mobile phone use while driving: Underestimation of a global threat", Journal of Transport and Health, Vol. 3 No. 1, pp. 4-8.

International Social Marketing Association, European Social Marketing Association and Australian Association of Social Marketing (2013), "The iSMA, ESMA and AASM consensus definition of social marketing", available at: www.i-socialmarketing.org/assets/social_marketing_definition. pdf (accessed 27 October 2019).

Janitzek, T. Brenck, A. Jamson, S. Carsten, O. and Eksler, V. (2010), "Study on the regulatory situation in the member states regarding brought-in (i.e. nomadic) devices and their use in vehicles: Final report", available at: https://etsc.eu/wp-content/uploads/Report_Nomadic_Devices.pdf (accessed 10 November 2019).

Job, R.F.S. (1988), "Effective and ineffective use of fear in health promotion campaigns", American Journal of Public Health, Vol. 78 No. 2, pp. 163-167.

Kok, G., Peters, G.-J.Y., Kessels, L.T.E., ten Hoor, G.A. and Ruiter, R.A.C. (2018), "Ignoring theory and misinterpreting evidence: the false belief in fear appeals”, Health Psychology Review, Vol. 12 No. 2, pp. 111-125. 
JSOCM 10,2

Lapinski, M.K. (2006), "StarvingforPerfect. com: a theoretically based content analysis of pro-eating disorder web sites", Health Communication, Vol. 20 No. 3, pp. 243-253.

Lapinski, M.K. and Witte, K. (1998), "Health communication campaigns", in Jackson, L.D. and Duffy, B. K. (Eds.) Health Communication Research: A Guide to Developments and Directions, Greenwood Press, Westport, CT, pp. 139-161.

LaVoie, N.R. and Quick, B.L. (2013), "What is the truth? an application of the extended parallel process model to televised truth ${ }^{\circledR}$ ads", Health Communication, Vol. 28 No. 1, pp. 53-62.

Lewis, I., Watson, B. and Tay, R. (2007), "Examining the effectiveness of physical threats in road safety advertising: the role of the third-person effect, gender, and age", Transportation Research Part F: Traffic Psychology and Behaviour, Vol. 10 No. 1, pp. 48-60.

Lewis, I., Watson, B. and White, K.M. (2013), "Extending the explanatory utility of the EPPM beyond fear-based persuasion”, Health Communication, Vol. 28 No. 1, pp. 84-98.

Lipovac, K., Đerić, M., Tešić, M., Andrić, Z. and Marić, B. (2017), "Mobile phone use while driving-literary review", Transportation Research Part F: Traffic Psychology and Behaviour, Vol. 47, pp. 132-142.

Michie, S., Johnston, M., Abraham, C., Lawton, R., Parker, D. and Walker, A. (2005), "Making psychological theory useful for implementing evidence based practice: a consensus approach", Quality and Safety in Health Care, Vol. 14 No. 1, pp. 26-33.

Miles, M.B. and Huberman, A.M. (1994), Qualitative Data Analysis: An Expanded Sourcebook, Sage, Thousand Oaks.

Mongeau, P.A. (2012), "Fear appeals", in Dillard, J.P. and Shen, L. (Eds.) The SAGE Handbook of Persuasion: Developments in Theory and Practice, 2 ed, Thousand Oaks, Sage pp. 184-199.

Mruk Ltd (2004), "Scottish executive evaluation of the 2003-2004 festive drink driving campaign", available at: www2.gov.scot/Resource/Doc/26350/0026590.pdf (accessed 11 November 2019).

Nelson, K., Cismaru, M., Cismaru, R. and Ono, T. (2011), "Water management information campaigns and protection motivation theory", International Review on Public and Nonprofit Marketing, Vol. 8 No. 2, pp. 163-193.

Ngondo, P.S. and Klyueva, A. (2019), "Fear appeals in road safety advertising: an analysis of a controversial social marketing campaign in Russia”, Russian Journal of Communication, Vol. 11 No. 2, pp. 167-183.

Nissan, M.E., Gupta, A., Rayess, H., Black, K.Z. and Carron, M. (2018), "Otoplasty online information: a comprehensive analysis of the websites and videos that patients view regarding cosmetic ear surgery", Facial Plastic Surgery, Vol. 34 No. 1, pp. 82-87.

Noar, S.M. (2004), "A health educator's guide to theories of health behavior", International Quarterly of Community Health Education, Vol. 24 No. 1, pp. 75-92.

Noar, S.M. (2006), "A 10-Year retrospective of research in health mass media campaigns: Where do We go from here?", Journal of Health Communication, Vol. 11 No. 1, pp. 21-42.

O'Cathain, A., Croot, L., Duncan, E., Rousseau, N., Sworn, K., Turner, K.M., Yardley, L. and Hoddinott, P. (2019), "Guidance on how to develop complex interventions to improve health and healthcare", BMJOpen, Vol. 9, p. e029954.

O'Keefe, D.J. (2006), "Message properties, mediating states, and manipulation checks: Claims, evidence, and data analysis in experimental persuasive message effects research", Communication Theory, Vol. 13 No. 3, pp. 251-274.

Peters, G.J.Y., Ruiter, R.A.C. and Kok, G. (2013), "Threatening communication: a critical re-analysis and a revised Meta-analytic test of fear appeal theory", Health Psychology Review, Vol. 7 No. S1, pp. S8-S31.

Peters, G.J.Y., Ruiter, R.A.C. and Kok, G. (2014), "Threatening communication: a qualitative study of fear appeal effectiveness beliefs among intervention developers, policymakers, politicians, scientists, and advertising professionals", International Journal of Psychology, Vol. 49 No. 2, pp. 71-79. 
Peters, G.J.Y., Ruiter, R.A.C., ten Hoor, G.A., Kessels, L.T.E. and Kok, G. (2018), “Towards consensus on fear appeals: a rejoinder to the commentaries on Kok, Peters, Kessels, ten Hoor, and Ruiter (2018)", Health Psychology Review, Vol. 12 No. 2, pp. 151-156.

Peters, L.W.H., Kok, G., Ten Dam, G.T.M., Buijs, G.J. and Paulussen, T.G.W.M. (2009), "Effective elements of school health promotion across behavioral domains: a systematic review of reviews", BMC Public Health, Vol. 9 No. 1.

Phillips, R.O., Ulleberg, P. and Vaa, T. (2011), "Meta-analysis of the effect of road safety campaigns on accidents", Accident Analysis and Prevention, Vol. 43 No. 3, pp. 1204-1218.

Quick, B.L., LaVoie, N.R., Reynolds-Tylus, T., Martinez-Gonzalez, A. and Skurka, C. (2018), "Examining mechanisms underlying fear-control in the extended parallel process model", Health Communication, Vol. 33 No. 4, pp. 379-391.

Renaud, D. and Unz, D. (2006), "Die M-DAS - eine modifizierte version der differentiellen affekt skala zur erfassung von emotionen bei der mediennutzung”, Zeitschrift Für Medienpsychologie, Vol. 18 No. 2, pp. 70-75.

Rogers, E.M. and Storey, J.D. (1987), "Communication campaigns", in Berger, C.R. and Chafee, S.H. (Eds), Handbook of Communication Science, Sage, London, pp. 817-846.

Rogers, R.W. (1975), "A protection motivation theory of fear appeals and attitude change", The Journal of Psychology, Vol. 91 No. 1, pp. 93-114.

Rosenstock, I.M. (1966), "Why people use health services", The Milbank Memorial Fund Quarterly, Vol. 44 No. 3, pp. 94-127.

Rothman, A.J. (2004), "Is there nothing more practical than a good theory?": why innovations and advances in health behavior change will arise if interventions are used to test and refine theory", International Journal of Behavioral Nutrition and Physical Activity, Vol. 1 No No. 1.

Schreier, M. (2012), Qualitative Content Analysis in Practice, Sage, Thousand Oaks.

Shen, L. (2011), "The effectiveness of empathy- versus fear-arousing antismoking PSAs", Health Communication, Vol. 26 No. 5, pp. 404-415.

Shen, L. (2015), "Antecedents to psychological reactance: the impact of threat, message frame, and choice”, Health Communication, Vol. 30 No. 10, pp. 975-985.

Shen, L. and Coles, V.B. (2015), "Fear and psychological reactance", Zeitschrift Für Psychologie, Vol. 223 No. 4, pp. 225-235.

Singh, R., Hsu, Y.-W. and Moon, N. (2013), "Multiple perspective interactive search: a paradigm for exploratory search and information retrieval on the web", Multimedia Tools and Applications, Vol. 62 No. 2, pp. 507-543.

Slater, M., Peter, J. and Valkenburg, P.M. (2015), "Message variability and heterogenity: a core challenge for communication research", in Cohen, E.L. (Ed.) Communication Yearbook, Vol. 39, Routledge, New York, NY, pp. 3-33.

Stead, M., Tagg, S., MacKintosh, A.M. and Eadie, D. (2004), "Development and evaluation of a mass media theory of planned behaviour intervention to reduce speeding", Health Education Research, Vol. 20 No. 1, pp. 36-50.

Steinmetz, H., Knappstein, M., Ajzen, I., Schmidt, P. and Kabst, R. (2016), "How effective are behavior change interventions based on the theory of planned behavior?", Zeitschrift Für Psychologie, Vol. 224 No. 3, pp. 216-233.

Storey, J.D., Hess, R. and Saffitz, G. (2015), "Social marketing”, in Glanz, K., Rimer, B.K. and Viswanath, K. (Eds.) Health Behavior: Theory, Research, and Practice, 5th ed., Jossey-Bass, San Fransisco, pp. 411-438.

Strayer, D.L. and Drew, F.A. (2004), "Profiles in driver distraction: Effects of cell phone conversations on younger and older drivers", Human Factors: The Journal of the Human Factors and Ergonomics Society, Vol. 46 No. 4, pp. 640-649.

Strayer, D.L. and Johnston, W.A. (2001), "Driven to distraction: dual-task studies of simulated driving and conversing on a cellular telephone”, Psychological Science, Vol. 12 No. 6, pp. 462-466. 
JSOCM 10,2

Tang, H. and Ng, J.H.K. (2006), "Googling for a diagnosis - use of Google as a diagnostic aid: internet based study”, BMJ, Vol. 333 No. 7579, pp. 1143-1145.

Tannenbaum, M.B., Hepler, J., Zimmerman, R.S., Saul, L., Jacobs, S., Wilson, K. and Albarracin, D. (2015), "Appealing to fear: a meta-analysis of fear appeal effectiveness and theories", Psychological Bulletin, Vol. 141 No. 6, pp. 1178-1204.

Tay, R. (2005), "Mass media campaigns reduce the incidence of drinking and driving", Evidence-Based Healthcare and Public Health, Vol. 9 No. 1, pp. 26-29.

Tay, R. and Watson, B. (2002), "Changing drivers' intentions and behaviours using Fear-Based driver fatigue advertisements", Health Marketing Quarterly, Vol. 19 No. 4, pp. 55-68.

Taylor, N., Conner, M. and Lawton, R. (2012), "The impact of theory on the effectiveness of worksite physical activity interventions: a Meta-analysis and Meta-regression", Health Psychology Review, Vol. 6 No. 1, pp. 33-73.

ten Hoor, G.A., Peters, G.-J.Y., Kalagi, J., de Groot, L., Grootjans, K., Huschens, A., Köhninger, C., Kölgen, L., Pelssers, I., Schütt, T., Thomas, S., Ruiter, R.A.C. and Kok, G. (2012), "Reactions to threatening health messages", BMC Public Health, Vol. 12 No. 1, p. 1011.

Valente, T.W. (2002), Evaluating Health Promotion Programs, Oxford University Press, Oxford.

Watson, S.I., Dixon-Woods, M., Taylor, C.A., Wroe, E.B., Dunbar, E.L., Chilton, P.J. and Lilford, R.J. (2019), "Revising ethical guidance for the evaluation of programmes and interventions not initiated by researchers", Journal of Medical Ethics, Published Online First: 03 September 2019, available at: https://doi.org/10.1136/medethics-2018-105263

Webb, T., Joseph, J., Yardley, L. and Michie, S. (2010), "Using the internet to promote health behavior change: a systematic review and Meta-analysis of the impact of theoretical basis, use of behavior change techniques, and mode of delivery on efficacy", Journal of Medical Internet Research, Vol. 12 No. 1, p. e4.

Wilde, G.J (1993), "Effects of mass media communications on health and safety habits: an overview of issues and evidence", Addiction, Vol. 88 No. 7, pp. 983-996.

Witte, K. (1992), "Putting the fear back into fear appeals: the extended parallel process model", Communication Monographs, Vol. 59 No. 4, pp. 329-349.

Witte, K. (1994), “The manipulative nature of health communication research", American Behavioral Scientist, Vol. 38 No. 2, pp. 285-293.

Witte, K. and Allen, M. (2000), "A Meta-analysis of fear appeals: Implications for effective public health campaigns", Health Education and Behavior, Vol. 27 No. 5, pp. 591-615.

Witte, K., Cameron, K.A., McKeon, J.K. and Berkowitz, J.M. (1996), "Predicting risk behaviors: development and validation of a diagnostic scale", Journal of Health Communication, Vol. 1 No. 4, pp. 317-342.

Wundersitz, L. and Hutchinson, T. (2011), "What can we learn from recent evaluations of road safety mass media campaigns?", Journal of the Australasian College of Road Safety, available at: http:// acrs.org.au/journals/november-2011-vol-22-no-4/

Wundersitz, L. Hutchinson, T. and Woolley, J. (2010), "Best practice in road safety mass media campaigns: a literature review", available at: http://casr.adelaide.edu.au/casrpubfile/972/ CASR074.pdf (accessed 13 November 2019).

\section{Corresponding author}

Svenja Diegelmann can be contacted at: Svenja.Diegelmann@aau.at

For instructions on how to order reprints of this article, please visit our website:

www.emeraldgrouppublishing.com/licensing/reprints.htm

Or contact us for further details: permissions@emeraldinsight.com 